\title{
Frequency of neuropathic pain and its effects on rehabilitation outcomes, balance function and quality of life among people with traumatic spinal cord injury
}

\author{
Muhammad Idrees Khan ${ }^{1}$, Aatik Arsh'2, \\ Ikram Ali ${ }^{3}$, Aman Khan Afridi ${ }^{4}$
}

\begin{abstract}
Background \& Objectives: Traumatic Spinal cord injury $(\mathrm{SCl})$ is a devastating condition that results in life long disability. Impairments associated with traumatic $\mathrm{SCl}$ such as sensory, motor, and autonomic dysfunctions lead to an array of secondary SCl-specific complications. Neuropathic pain is one of the most common medical complications of traumatic $\mathrm{SCl}$ which significantly affects motor function and activities of daily living (ADL) in people with traumatic $\mathrm{SCl}$. Neuropathic pain is one of the main factors for dependency, decreased quality of life (QOL), poor rehabilitation outcomes, and depression in traumatic $\mathrm{SCl}$ individuals. The main aim of the current study was to determine the frequency of neuropathic pain and its effects on rehabilitation outcomes, balance function, and QOL in people with traumatic $\mathrm{SCl}$.

Methods: A cross-sectional survey was carried out at PCP from March to August 2020. Overall, 123 participants were added to the study using a non-probability convenience sampling technique. Information was collected using an adapted, validated questionnaire. Both male and female traumatic $\mathrm{SCl}$ patients with age between 18-60 years who received at least two weeks of rehabilitation, 42 days after diagnosis of traumatic $\mathrm{SCl}$ were included in current study while patients with Acute $\mathrm{SCl}, \mathrm{SCl}$ patients with any other condition which can affect neuropathic pain such as traumatic brain injury, diabetic neuropathy, amputation, etc. and progressive neurological diseases such as multiple sclerosis and Guillain barre syndromes were excluded. Patients who have received at least two weeks of rehabilitation, 42 days after diagnosis of traumatic $\mathrm{SCl}$. Patients with traumatic $\mathrm{SCl}$.

Results: Overall, 123 traumatic SCI patients were included in the study. The majority of the $(\mathrm{n}=101$, 82\%) participants were male and 83 (67.5\%) were from urban areas. Eighty-Seven (70.73\%) participants had neuropathic pain. Neuropathic pain was significantly associated $(P$-value $<0.005)$ with rehabilitation outcomes, balance function, and quality of life.

Conclusion: It can be concluded that more than two-third of $\mathrm{SCl}$ patients suffer from neuropathic pain. Moreover, neuropathic pain is significantly associated with rehabilitation outcomes, balance function, and quality of life.
\end{abstract}

KEYWORDS: Neuropathic Pain, Rehabilitation outcomes, Balance Function, Quality of Life, Traumatic Spinal cord injury.

doi: https://doi.org/10.12669/pjms.38.4.4681

How to cite this:

Khan MI, Arsh A, Ali I, Afridi AK. Frequency of neuropathic pain and its effects on rehabilitation outcomes, balance function and quality of life among people with traumatic spinal cord injury. Pak J Med Sci. 2022;38(4):888-892. doi: https://doi.org/10.12669/pjms.38.4.4681

This is an Open Access article distributed under the terms of the Creative Commons Attribution License (http://creativecommons.org/licenses/by/3.0), which permits unrestricted use, distribution, and reproduction in any medium, provided the original work is properly cited.

Correspondence:

Muhammad Idrees Khan, DPT, MSPT.

E-mail: idreesymht104@gmail.com

* Received for Publication:

* $1^{\text {st }}$ Revision Received:

* $2^{\text {nd }}$ Revision Received:

* Final Revision Accepted:
May 6, 2021

June 8, 2021

December 3, 2021

December 28, 2021

\section{INTRODUCTION}

Traumatic SCI is a devastating condition that results in lifelong disability. ${ }^{1}$ Impairments associated with traumatic SCI such as sensory, motor, and autonomic dysfunctions lead to an array of secondary SCI-specific complications. ${ }^{2}$ Neuropathic 
pain is one of the most common medical complications of traumatic SCI which significantly affects motor function and ADL in people with traumatic SCI. ${ }^{3}$ Neuropathic pain increases patient dependency, decreases patient's QOL, poor rehabilitation outcomes, and promotes psychological problems in traumatic SCI individuals. ${ }^{4}$ Globally, 27 to $94 \%$ of traumatic SCI patients suffer from neuropathic pain. ${ }^{4}$ In Pakistan, the reported prevalence of neuropathic pain ranges from 17 to $57.5 \% .{ }^{5}$ With the passage of time and effective measures, the number of traumatic SCI individuals may decrease. ${ }^{6}$ There is one patient out of tens of patients of traumatic SCI patients having neuropathic pain. If this ratio continues, the number is expected to be one out of five patients and so on one out of three in $2051 .{ }^{7}$

The symptoms of neuropathic pain generally persist for long durations. ${ }^{8}$ The neuropathic pain symptoms often do not respond to pharmacological and electrotherapeutic modalities. ${ }^{9}$ Previous studies have reported that neuropathic pain increases the suffering of traumatic SCI individuals. ${ }^{10}$ With the increase in symptoms of neuropathic pain, the physical function of the human body decline, and the individuals suffers from various health problems. ${ }^{11}$ Traumatic SCI patients with neuropathic pain are confronting a wide range of psychological problems which in turn reduces the effectiveness of rehabilitation interventions. ${ }^{12}$ These patients had poor compliance with physical and occupational therapy and they have a longer length of stay at rehabilitation centers. ${ }^{13}$ Due to all these reasons, the treatment of the traumatic SCI patients with neuropathic pain is more expensive as compared to the traumatic SCI patients without neuropathic pain. ${ }^{14}$

Neuropathic pain is a disabling condition that restricts patients from performing ADLs and affects the patient's QOL. ${ }^{15}$ Limited physical activity causes many health-related problems in traumatic SCI patients such as the immune system becomes weak which may also lead to many diseases. ${ }^{16}$ The majority of the diseases in traumatic SCI patients are due to the change in lifestyle, emotional impact, social circumstances, nutrition, and psychosocial health. ${ }^{17}$

\section{METHODS}

A cross-sectional study was conducted in PCP, Khyber Pakhtunkhwa, Pakistan. This hospital is a semi-government hospital located at the center of Khyber Pakhtunkhwa. This hospital covers 80\% of the SCI population of the KPK province and considers a hub for all rehabilitation sector hospitals. Participants who fulfilled the inclusion criteria have been selected from different departments of that hospital. The study was conducted in six months (March 1', 2020 to August 30 $0^{\text {th }}, 2020$ ).

The study was conducted after the approval of ASRB and Khyber Medical University's ethical and research committee, letter no. DIR/KMU-EB/FA000792 dated 5-6-2020. The approval for the data collection was granted on the basis of said ethical report by Chief Executive Officer of the Paraplegic Center Peshawar. Before data collection, the aims and objectives of the study were elaborated to the subjects and the concerns of the participants were cleared. After this, the participants were selected via non-probability convenience sampling technique for the current study. There were enough traumatic SCI patients in that hospital that were easily accessed through non-probability convenience sampling. Initially, the list of traumatic spinal cord injury patients in the hospital was collected. After that 123 traumatic spinal cord injury patients who fulfilled the inclusion criteria were selected from different units of the hospital.

Inclusion \& Exclusion criteria: The patient included were male and female traumatic SCI patients age 1860 years, patients who received at least two weeks of rehabilitation, 42 days after diagnosis of traumatic SCI and Patients only having traumatic SCI. Similarly the excluded candidates for the study were Acute SCI patients, SCI patients with any other condition which can affect neuropathic pain such as traumatic brain injury, diabetic neuropathy, amputation, etc. and progressive neurological diseases such as multiple sclerosis and Guillain barre syndromes.

The data was collected using adapted questionnaires such as LANSS pain scale, SCIM, functional reach test, and WHO-QOL BREF among traumatic SCI patients. The questionnaire consisted of five sections. Section "A" covered demographic data. There were fifteen questions in section " $\mathrm{A}$ " regarding the age of the participants, gender, residence, marital status, occupation, height, weight, BMI, date Injury, cause of injury, radiological sign, spinal fixation, neurological Level, ASIA impairment scale and contact number.

The section " $\mathrm{B}$ " consisted of seven questions based on pain and sensory testing of traumatic SCI Patients. The first five questions were painrelated while the last two were symptoms related. The total score on the LANSS scale was 24. Those patients having pain score greater or equal to 12 were considered neuropathic pain while in patients having pain score less than 12 on the LANSS scale were considered non-neuropathic pain. 
Section "C" consisted of two portions. The first portion was about the self-care of the patients have further four parts (1) Feeding (2) Bathing (3) Dressing (4) Grooming while the second portion was about the mobility of the patients. It had two parts. The first part was about indoor activity and other part was about outdoor activity.

Section " $\mathrm{D}$ " also consisted of two portions. The first portion was about the forward reach of both the right and left side of the patients while the second portion was about the lateral reach of the right and left side of the patients.

Section "E" was divided into four domains. These four domains included the physical health of the patients, psychological state of the patients, social relationship of the patients and the environment of the patients.

\section{RESULTS}

Overall included participants in this study were 123 in which no participant quit the study. All the participants were traumatic SCI patients admitted in different units of PCP, Khyber Pakhtunkhwa. The maximum age of the participants was 60 years while the minimum age of the participants was 18 years. The mean age of the participants is 33.52 with a standard deviation of \pm 11.52 . Analysis of the study showed that the majority $(82.11 \%)$ of

Table-I: Demographic profile of traumatic spinal cord injury patients $(\mathrm{N}=123)$.

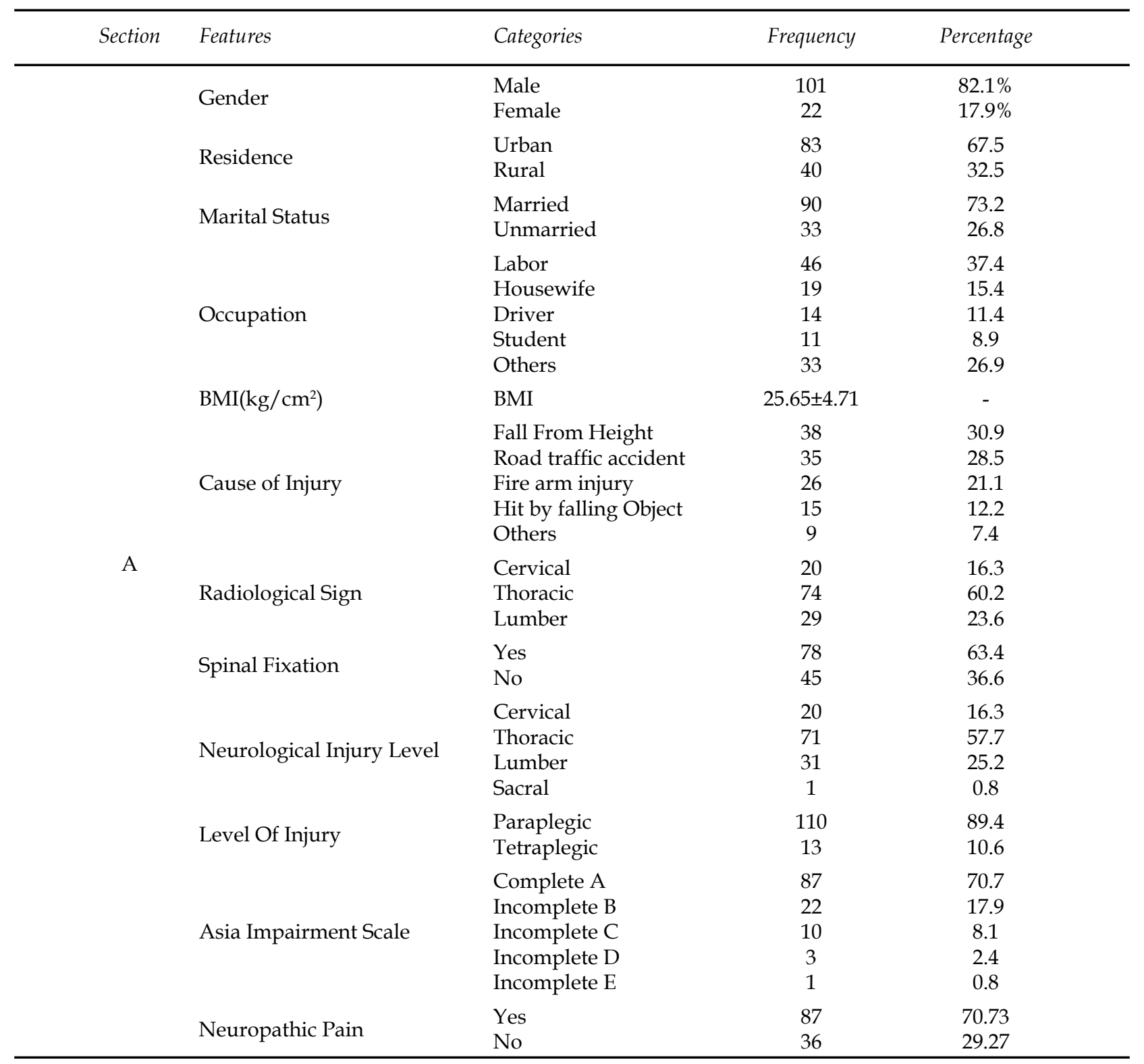


Table-II: Neuropathic pain in traumatic spinal cord injury patients ( $\mathrm{N}=123)$.

\begin{tabular}{clcc}
\hline Section & Neuropathic Pain & Number & Percentage \\
& Patients with neuropathic pain & 87 & $70.73 \%$ \\
B & Patients without neuropathic pain & 36 & $29.27 \%$ \\
\hline
\end{tabular}

the study participants were male while $(17.9 \%)$ were female.

Results declared that the majority $(67.5 \%)$ of the study participants were reported from the urban area while $(32.5 \%)$ SCI patients were noted from rural areas. The majority $(30.09 \%)$ of the cause of injury of the participants was fall from a height, followed by road traffic accident $(28.5 \%)$, fire arm injury $(21.1 \%)$, hit by falling object $(12.2 \%)$, coal mine accident (4.1), and fall on the ground (Table-I).

The majority of the participants responded that their rehabilitation outcomes were affected by neuropathic pain because the study analysis shows that his p-value was below 0.05 .

The majority $(70.73 \%)$ of the traumatic SCI patients had neuropathic pain; followed by $(29.27 \%)$ of traumatic SCI had no neuropathic pain (Table-II).

\section{DISCUSSION}

The current study conducted shows that majority of the participants level injury is paraplegic and the ASIA impairment scale is complete. The basic purpose of the current study was to assess the frequency of neuropathic pain in traumatic SCI patients. The current study revealed that the majority $\mathrm{n}=87(70.73 \%)$ patients had average signs and symptoms regarding neuropathic pain in traumatic SCI patients. As discussed earlier $70.73 \%$ of patients suffered from neuropathic pain in traumatic spinal cord injury while $29.27 \%$ had no pain. This rate was found to be higher at $17.73 \%$ than the previously reported study (53\%) conducted by Burke $\mathrm{D}$ et al. ${ }^{18}$ Moreover, it also indicated a higher rate of neuropathic pain as compared to previously reported study conducted in the USA regarding the neuropathic pain in which prevalence ranged from $21 \%$ to $60 \%$ among the SCI population. ${ }^{19-20}$ In the same context, a study conducted in the UK to identify neuropathic pain showed that $70 \%$ of the SCI patients had signs and symptoms of neuropathic pain which is almost similar to the results of current study. ${ }^{21-22}$ Similarly, one of the study conducted in Australia reported higher percentage $(77.3 \%)$ of the SCI patients as compared to the current study. ${ }^{23} \mathrm{~A}$

Table-III: Neuropathic pain and its effect on rehabilitation outcomes, balance and QOL.

\begin{tabular}{|c|c|c|c|c|}
\hline Section & $\begin{array}{l}\text { Neuropathic pain and its effect on } \\
\text { rehabilitation outcomes, balance }\end{array}$ & \multicolumn{2}{|c|}{ Neuropathic pain } & P-Value \\
\hline \multirow{4}{*}{ C } & & Yes $(n=87)$ & No $(n=36)$ & \\
\hline & Rehabilitation outcomes & & & \\
\hline & Self -care & $13.43 \pm 3.70$ & $11.86 \pm 4.20$ & 0.041 \\
\hline & Mobility & $12.86 \pm 8.46$ & $17.30 \pm 11.77$ & 0.020 \\
\hline \multirow{5}{*}{$\mathrm{D}$} & Balance function & & & \\
\hline & FRT Right-Hand & $17.44 \pm 7.93$ & $21.20 \pm 7.93$ & 0.016 \\
\hline & FRT Left-Hand & $20.15 \pm 6.49$ & $17.13 \pm 7.98$ & 0.030 \\
\hline & LRT Right-Hand & $21.47 \pm 8.0$ & $18.13 \pm 7.89$ & 0.037 \\
\hline & LRT Left-Hand & $19.17 \pm 6.79$ & $16.36 \pm 7.41$ & 0.044 \\
\hline \multirow{5}{*}{$\mathrm{E}$} & Quality of life & & & \\
\hline & Physical Health & $23.55 \pm 2.20$ & $22.53 \pm 2.52$ & 0.027 \\
\hline & Psychological & $19.79 \pm 2.59$ & $21.00 \pm 3.07$ & 0.028 \\
\hline & Social Relationship & $9.69 \pm 1.49$ & $9.06 \pm 1.33$ & 0.029 \\
\hline & Environmental & $28.20 \pm 2.72$ & $29.31 \pm 2.95$ & 0.047 \\
\hline
\end{tabular}

FRT: Functional reach test, LRT: lateral reach test, * paired sample T test. 
study conducted in the USA reported that neuropathic pain had a bad effect on rehabilitation outcomes and balance function in SCI patients which is in concurrence to the current study. ${ }^{24-25}$ It was observed druing the current study that neuropathic pain also effects the QOL of the SCI patients. It was also reported by De Oliveira B et. al that neuropathic pain effect QOL in SCI patients. ${ }^{26}$

Limitation of the study: Traumatic SCI patients from paraplegic center Peshawar were included in the study, nearly half of the traumatic SCI population admitted in tertiary care hospitals and private hospitals. It would be good if data were collected from traumatic SCI patients admitted in tertiary care hospitals. Time constraint is another limitation of the study.

\section{CONCLUSION}

The research findings showed that neuropathic pain is one of the main issue among traumatic SCI patients.It can effect the rehabilitation outcomes, balance function and quality of life which can ultimately effect the general health status of such patients. Proper management and prognosis of neuropathic pain is important to improve the individual's quality of life.This study will help in the management of effective therapeutic options by understanding the relevance of neuropathic pain among these patients.

\section{Grant Support E Financial Disclosures: None. \\ REFERENCES}

1. Lee S, Zhao X, Hatch M, Chun S, Chang EY. Central neuropathic pain in spinal cord injury. Crit Rev Phys Rehabil Med. 2013;25(3-4). doi: 10.1615/CritRevPhysR ehabilMed.2013007944

2. Bakhsh A. Long-Term Complications of Chronic Traumatic Paraplegia: An Experience from Pakistan. Cureus [online]. 2013;5:e116. doi: 10.7759/cureus.116

3. Selassie A, Cao Y, Saunders LL. Epidemiology of traumatic spinal cord injury among persons older than 21 years: A population-based study in South Carolina 1998-2012. Top

4. Hadjipavlou G, Cortese AM, Ramaswamy B. Spinal cord injury \& chronic pain BJA Educ. 2016;16(8):264-268. doi: 10.1093/bjaed/mkv073

5. Zeb A, Arsh A, Bahadur S, Ilyas SM. Effectiveness of transcutaneous electrical nerve stimulation in management of neuropathic pain in patients with post traumatic incomplete spinal cord injuries. Pak J Med Sci. 2018;34(5):1177-1180, doi: $10.12669 /$ pims.345.15659.

6. Teasell RW, Mehta S, Aubut J-AL, Foulon B, Wolfe DL, Hsieh JT, et al. A systematic review of pharmacologic treatments of pain after spinal cord injury. Arch Phys Med Rehabil. 2010;91(5):816-831. doi: 10.1016/j.apmr.2010.01.022/

7. Finnerup NB, Johannesen I, Sindrup SH, Bach FW, Jensen TS. Pain and dysesthesia in patients with spinal cord injury: A postal survey. Spinal Cord. 2001;39(5):256262 doi: $10.1038 /$ sj.sc 3101161

8. Ullah H, Ayaz SB, Akhtar N, Matee S, Butt AW. Frequency, character, intensity and impact of neuropathic pain in a cohort of spinal cord injury patients. Pak Armed Forces Med J. 2015;65(2):239-242.

9. Rathore MF, Rashid P, Butt AW, Malik AA, Gill ZA, Haig AJ. Epidemiology of spinal cord injuries in the 2005 Pakistan earthquake. Spinal Cord. 2007;45(10):658663. doi: 10.1038 /sj.sc. 3102023

10. Guy SD, Mehta S, Harvey D, Lau B, Middleton JW, O'Connell C, et al. The CanPain SCI Clinical Practice Guideline for Rehabilitation Management of Neuropathic Pain after Spinal Cord: recommendations for model systems of care. Spinal Cord. 2016;54(Suppl-1):S24-S27. doi: 10.1038/sc.2016.91

11. Darain H, Arsh A. Spinal cord injury and its associated challenges to rehabilitation of patients in Pakistan. Rehman J Health Sci. 2019;1(1):1-2.

12. Hollingshead J, Duhmke R, Cornblath D. Tramadol for neuropathic pain Cochrane Database Syst Rev. 2006;3:37-26 doi: 10.1002/14651858.CD003726.pub3.
13. Shiao R, Lee-Kubli CA. Neuropathic Pain After Spinal Cord Injury: Challenges and Research Perspectives. Neurotherapeutics. 2018;15(3):635-653. doi: 10.1007/ s13311-018-0633-4

14. Hicks A, Martin K, Ditor D, Latimer A, Craven C, Bugaresti J, et al. Long-term exercise training in persons with spinal cord injury: effects on strength, arm ergometry performance and psychological well being. Spinal Cord. 2003;41(1):3443. doi: $10.1038 /$ s..sc. 3101389

15. van Koppenhagen CF, Post MW, van der Woude LH, de Witte LP, van Asbeck FW, de Groot S, et al. Changes and determinants of life satisfaction after spinal cord injury: a cohort study in the Netherlands. Arch Phys Med Rehabil. 2008;89(9):1733-1740 doi: 10.1016/j.apmr.2007.12.042

16. Arsh A, Darain H, Ilyas SM, Zeb A. Consequences of traumatic spinal cord in jury during pregnancy in Pakistan. Spinal Cord Series Cases. 2017;3(1):1-4. doi 10.1038 /scsandc. 2017.41

17. Khazaeipour Z, Taheri-Otaghsara S-M, Naghdi M. Depression following spina cord injury: its relationship to demographic and socioeconomic indicators. Top Spinal Cord Inj Rehabil. 2015;21(2):149-155. doi: 10.1310/sci2102-149

18. Burke D, Fullen BM, Stokes D, Lennon O. Neuropathic pain prevalence following spinal cord injury: A systematic review and meta-analysis. Eur J Pain 2017;21(1):29-44. doi: 10.1002/ejp.905

19. Harkema SJ, Schmidt-Read M, Lorenz DJ, Edgerton VR, Behrman AL. Balance and ambulation improvements in individuals with chronic incomplete spinal cord injury using locomotor training-based rehabilitation. Arch Phys Med Rehabil. 2012;93(9):1508-1517. doi: 10.1016/j.apmr.2011.01.024

20. Shapkova EY, Pismennaya EV, Emelyannikov DV, Ivanenko Y. Exoskeleton walk training in paralyzed individuals benefits from transcutaneous lumbar cord tonic electrical stimulation. Front Syst Neurosci. 2020;14. doi: 10.3389/fnins.2020.00416

21. Shah SZA, llyas SM. Assessment of the quality of life of spinal cord injury patients in Peshawar. J Pak Med Assoc. 2017;67(3):434-437. doi: 10.36570/jduhs.2020.1.900

22. Qureshi MA, Khalique AB, Pasha IF, Asad A, Malik AS, Shah M, et al. Epidemiology of non-disaster spinal injuries at a spine unit. J Coll Physicians Surg Pak. 2010:20(10):667-670 doi: 10.1179/1079026812Z.00000000061

23. Colloca L, Ludman T, Bouhassira D, Baron R, Dickenson AH, Yarnitsky D, et al. Neuropathic pain. Nature Rev Dis Primers. 2017;3(1):1-19. doi: 10.1038/nrdp.2017.2 24. Hadjipavlou G, Cortese A, Ramaswamy B. Spinal cord injury and chronic pain. BJA Educ. 2016;16(8):264-268 doi: 10.1093/bjaed/mkv073

25. O'Connor PJ. Survival after spinal cord injury in Australia. Arch Phys Med Rehabil. 2005;86(1):37-47. doi: 10.1016/j.apmr.2007.09.027

26. De Oliveira B, Howie E, Dunlop S, Galea M, McManus A, Allison G. SCIPA Com: outcomes from the spinal cord injury and physical activity in the community intervention. Spinal Cord. 2016;54(10):855-860. doi: 10.1080/10790268.2018.1543104

\section{Authors' Contribution:}

MIK: Concept and study design, literature search and literature review, acquisition of data,drafting the manuscript,final approval of the version to be published. He is responsible for the accuracy or intergerity of the work. AA: Overall supervision,drafting the manuscript,analysis and interpretation of data. IA: Literature search and literature review,critical revision. AKF:Concept and study design,critical revision.

Authors:

1. Muhammad Idrees Khan, DPT, MSPT.

Lecturer,

2. Aatik Arsh, DPT, MSPT.

Assistant Professor

3. Ikram Ali, BSPT, TDPT, MSPT.

Assistant Professor,

4. Aman Khan Afridi, DPT, MSPT. Lecturer,

1, 4: Department of Health Sciences, City University Peshawar, Pakistan.

2, 3: Institute of Physical Medicine and Rehabilitation, Khyber Medical University Peshawar, Pakistan.

\section{Correspondence:}

Muhammad Idrees Khan, DPT, MSPT.

Lecturer,

Department of Health Sciences,

City University Peshawar, Pakistan.

E-mail: idreesymht104@gmail.com 